\title{
Restrictive versus Standard Fluid Regimen in Elective Minilaparotomy Abdominal Aortic Repair-Prospective Randomized Controlled Trial
}

\author{
Dragan Piljic ${ }^{1} \quad$ Mate Petricevic $^{2} \quad$ Dilista Piljic $^{3} \quad$ Jus Ksela $^{4}$ Boris Robic ${ }^{5}$ Tomislav Klokocovnik ${ }^{4}$
}

1 University of Tuzla School of Medicine, Department of Cardiovascular Surgery, University Clinical Center Tuzla, Tuzla, Bosnia and Herzegovina

2 University of Zagreb School of Medicine, Department of Cardiac Surgery, University Hospital Center Rebro, Zagreb, Croatia

3 University of Tuzla School of Medicine, University Clinical Center

Tuzla, Tuzla, Bosnia and Herzegovina

${ }^{4}$ University of Ljubljana School of Medicine, Department of Cardiovascular Surgery, University Clinical Center Ljubljana, Ljubljana, Slovenia

${ }^{5}$ Department of Cardiothoracic Surgery, Jessa Hospital, Hasselt, Belgium
Address for correspondence Dragan Piljic, MD, PhD, Department of Cardiovascular Surgery, University Clinical Center Tuzla, Trnovac bb, Tuzla 75000, Bosnia and Herzegovina (e-mail: dragan.piljic@dr.com).

Thorac Cardiovasc Surg

\begin{abstract}
Keywords

- aneurysm

- aorta/aortic

- blood transfusion

Objective Elective minilaparotomy abdominal aortic aneurysm (AAA) repair is associated with a significant number of complications involving respiratory, cardiovascular, gastrointestinal, and central nervous systems, with mortality ranging up to $5 \%$. In our study, we tested the hypothesis that intra- and postoperative intravenous restrictive fluid regimen reduces postoperative morbidity and mortality, and improves the outcome of minilaparotomy AAA repair.

Methods From March 2009 to July 2013, 60 patients operated due to AAA were included in a prospective randomized controlled trial (RCT). About the administration of fluid during the operation and in the early postoperative period, all the patients were randomized into two groups: the group of standard fluid administration (S-group, 30 patients) and the group of reduced fluid administration (R-group, 30 patients). The verification of the treatment success was measured by the length of intensive care unit (ICU) stay, duration of hospitalization after the procedure, as well as the number and type of postoperative complications and mortality. This prospective RCT was registered in a publicly accessible database ClinicalTrials.gov with unique Identifier ID: NTC01939652.

Results Total fluid administration and administration of blood products were significantly lower in R-group as compared with S-group $(2,445.5 \mathrm{~mL}$ vs. $3308.7 \mathrm{~mL}$, $p=0.004)$. Though the number of nonlethal complications was significantly lower in R-group ( 2 vs. 9 patients, $p=0.042$ ), the difference in lethal complications remained nonsignificant ( 0 vs. 1 patient, $p=n$ s). The average ICU stay (1.2 vs. 1.97 days, $p=0.003$ ) and duration of postoperative hospital stay (4.33 vs. 6.20 days, $p=0.035$ for R-group and S-group, respectively) were found to be significantly shorter in R-group. Conclusion Intra- and postoperative restrictive intravenous fluid regimen in patients undergoing minilaparotomy AAA repair significantly reduces postoperative morbidity,
\end{abstract}

received

December 15, 2014

accepted after revision

January 30, 2015 (c) Georg Thieme Verlag KG

Stuttgart · New York
DOI http://dx.doi.org/ 10.1055/s-0035-1548736. ISSN 0171-6425. 
and shortens ICU and overall hospital stay. Even though incidence of lethal complication was lower in R-group, the difference did not reach statistical significance. Therefore, we may assume that this study was probably underpowered to estimate the differences in mortality between R- and S-groups. Further multicentric, sufficiently powered RCTs are needed to confirm these findings and to clarify effect of restrictive fluid management on mortality.

\section{Introduction}

Minilaparotomy is a novel surgical approach used for elective operations of infrarenal abdominal aortic aneurysm (AAA) as well as aortoiliac occlusive disease. By this technique, AAA is accessed through an 8- to $10-\mathrm{cm}$ paraumbilical incision. By using the abdominal retractor and abdominal pads, the small and large bowels are retracted to the side without being elevated out of the abdominal cavity as case in conventional full laparotomy approaches. ${ }^{1}$ Minilaparotomy has a potential benefit for the patient, including shorter postoperative intubation period, shorter ICU and overall hospital stay, reduced risk of infection and postoperative pain, and smaller wound size with aesthetically more acceptable scar. ${ }^{2}$

Surgical trauma to the tissue, tissue hypoperfusion due to inadequate fluid regimen, ischemia, reperfusion injury, inflammation, and sepsis are recognized mechanisms that destroy vascular integrity. The consequence of this is the loss of fluid, with gradual redistribution between intracellular, interstitial, and intravascular space causing dehydration that might lead to acute hypovolemia. ${ }^{3}$ Pathogenesis of late postoperative hypoxemia includes endocrine-metabolic stress activation, pulmonary dysfunction, and disturbed sleeping. ${ }^{4}$ Late night postoperative hypoxemia (constant and periodical) is described extensively in second and third postoperative night, which may be related to cardiovascular and cerebral dysfunction. ${ }^{5}$ An increase in extracellular fluid in intestines might lead to gastrointestinal edema and raises gastrointestinal dysfunction. ${ }^{6}$ Excessive fluid administration might lead to the syndrome of abdominal compartment, which is defined as postoperative or posttraumatic increase in intra-abdominal pressure, causing unfavorable physiologic effects, most frequent of which are respiratory insufficiency and kidney failure, and edema of the pancreas, intestinal nutritive intolerance, extended intestinal paralysis, as well as translocation of endotoxin and bacteria into the blood, including occurrence of sepsis and multiorgan failure. ${ }^{7}$

In early postoperative period, patients require fluid administration be it for compensation of fluid loss due to preoperative fluid intake restrictions, perspiration lost, shift of fluid toward the third space, or due to blood loss pertaining to the surgery procedure itself.

Either colloid or crystalloid fluids may be administered, and decision to administer colloids or crystalloids often depends on many patient specifics as well as on anesthesiologists' preference. Smaller volume loss may be compensated by crystalloid solutions such as Ringer lactate or isotonic saline in amount of three times as much comparing to the loss of volume from the intravascular space.

The main goal of intraoperative fluid administration is to maintain tissue perfusion, by optimizing the volume status and stroke volume. Defining intravascular volume in operating theater still remains a challenge due to rapid changes in physiology and intraoperative loss of volume. In addition, the main condition leading to the need for surgical intervention may be related to suboptimal preoperative volume status. ${ }^{8}$ Standard fluid administration protocols use the predetermined algorithms of fluid administration and replacement of fluid lost in the "third space," invisible losses of fluid, as well as urinary losses. ${ }^{9}$ Restrictive fluid administration avoids fluid overload, by replacing only the fluid that is lost during the operation. ${ }^{4,9}$

In this prospective multicenter randomized trial, we sought to evaluate whether restrictive fluid management provides more favorable clinical outcomes in terms of morbidity and mortality, when comparing to standard fluid administration management.

\section{Patients and Methods}

The prospective multicenter RCT was approved by Scientific Ethics Committee of the University Clinical Centre Tuzla and the University Clinical Centre Ljubljana, and was registered on a publicly accessible database (www.clinicaltrials.gov) with unique identifier (NTC01939652).

\section{Patients}

Sixty patients with a diagnosis of infrarenal AAA who were admitted to respective institutions for an elective surgical repair were included in a prospective randomized trial.

We perform minilaparotomy approach for small aneurysms because our health care system allowed limited number of endovascular procedures for AAAs.

Inclusion criteria were isolated stable infrarenal AAA exceeding $5.5 \mathrm{~cm}$ with normal dimension of supra- and juxtarenal aorta and iliac arteries.

Exclusion criteria were emergency operations due to AAA rupture, previous abdominal surgery with laparotomy being performed for any pathology, liver, thyroid, or renal failure on dialysis, preoperative anemia, and any systemic or malignant disease. AAA repair with planned aorto-bifemoral or aortobi-iliac graft minilaparotomy was also considered to be exclusion criterion as this procedure results in increased surgical stress and operative time. 
Preoperative demographic and clinical data were collected and recorded.

POSSUM (Physiological and Operative Severity Score for the enUmeration of Mortality and morbidity) scoring system uses a physiologic and an operative severity parameters to calculate risks of mortality and morbidity. It is based on 12 physiologic (age, cardiac, respiratory, electrocardiogram, systolic blood pressure, pulse rate, hemoglobin, white blood cell count, urea, sodium, potassium, Glasgow coma score) and 6 operative (procedure type, number of procedures, operative blood loss, peritoneal contamination, malignancy, and urgency status) parameters to predict mortality risk of patients considered for surgical procedures.

After both oral and written consent, patients were randomized by the sealed envelope method (serially numbered, externally generated, and computer-generated random numbers) to the restricted (R-group) or standard (S-group) fluid regimen (-Fig. $\mathbf{1}$ ).

\section{Outcome Definition}

Outcomes were defined as primary and secondary.

Primary outcomes were defined as follows: 30-days mortality, length of ICU stay, length of hospital stay. Perioperative mortality included lethal outcome in the period from the operation until 30 days after the operation, which was a priori defined as a follow-up period.

Secondary outcomes were divided into few subgroups such as: (1) cardiovascular (myocardial infarction, arrhythmia, cardiac failure); (2) respiratory (pneumonia, pulmonary edema, respiratory failure); (3) thrombotic (thrombosis, embolism); (4) hemorrhagic (reexploration for bleeding); (5) renal (renal failure); (6) infections (wound dehiscence, other infections); (7) neurologic (depression, acute delirium); (8) gastrointestinal (obstipation, vomiting, ileus).

\section{Perioperative Management}

Induction of anesthesia was performed in a standardized manner with fentanyl, midazolam, and vecuronium bromide, and maintained by inhalational anesthetics. All operations

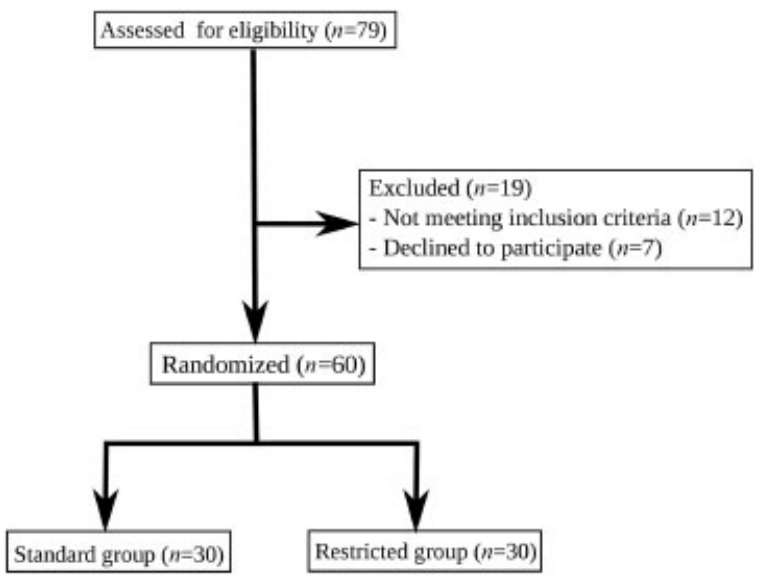

Fig. 1 Consort statement on conscription and randomization of patients. were performed through 8 - to 10 -cm-long paraumbilical laparotomy incision (i.e., minilaparotomy)., ${ }^{1,2}$ Put briefly, the intestines were drawn laterally using abdominal pads and retractors, and the aorta was approached from the anterior side through the incision in the peritoneum. After the dissection of the para-aortic tissue, heparin at a dose of 5,000 IU was applied, and the aorta and the iliac arteries above and below the aneurysm clamped. Standard endoaneurysmorrhaphy using tubular graft was performed. During the operation basic clinical and surgical parameters (arterial blood pressure heart rate and central venous pressure) were documented. After the procedure all the patients were transferred to the ICU and continuously monitored for the first 2 days. Later on, clinical observation and supervision were performed until the discharge from the hospital. Following discharge, follow-up was done twice a week and records of both primary and secondary outcomes were obtained until the postoperative day 30 .

\section{Fluid Management}

Patients in perioperative period require fluids administration to either compensate volume loss caused by preoperative fluid restriction or perioperative fluid shift toward the third space, fluid loss through perspiration, and finally blood loss due to surgical procedure itself.

Smaller loss could be compensated with crystalloids such as Ringer lactate or isotonic saline. Essentially, it is necessary to infuse at least three times higher quantity from the amount of blood loss to adequately compensate intravascular space loss.

In a case of hypovolemia, followed by adequate hematocrit and hemoglobin, we usually administer colloids, but in cases where hypotension is persisting and hematocrit is less 0.3 (30\%), we infuse colloids to fill intravascular space, but in combination with crystalloid in colloid: crystalloid ratio of $1: 2$.

In patients at risk for excessive bleeding, (15-20\% of blood loss in adults), in particular in elderly patients, we consider administration of blood products.

Patients in control arm received standard volume of fluids (S-group) whereas patients in intervention arm received a restrictive volume of fluid (R-group). We determined in our study intraoperative fluid intake to be $10 \mathrm{~mL} /$ $\mathrm{kg} / \mathrm{h}$ in R-group and $15 \mathrm{~mL} / \mathrm{kg} / \mathrm{h}$ in S-group, respectively. Postoperative fluid intake was $150-200 \mathrm{~mL} / \mathrm{h}$ in S-group. In $\mathrm{R}$-group we decided to apply restrictive fluid regimen between 70 and $100 \mathrm{~mL} / \mathrm{h}$ the three consecutive postoperative days. In both regimens, blood component therapy was administered when estimated blood loss presented with hematocrit less than $30 \%$.

\section{Statistical Analysis}

Smirnov-Kolmogorov test was used to assess the normality of data distribution. All the results were reported as mean and confidence interval. Student $t$, and $\mathrm{X}^{2}$-tests were used for calculating numerical data. A $p$ value of $<0.05$ was considered statistically significant. SPSS statistics software package was used for statistical analysis. 
Fluid Regimen in Elective Minilaparotomy Abdominal Aortic Repair Piljic et al.

\section{Results}

Sixty patients operated in University clinical center Tuzla, Bosnia and Herzegovina and University clinical center Ljubljana, Slovenia were operated on for infrarenal AAA using minilaparotomy approach and were subsequently included in the study.

No differences were observed between groups in regard to demographic characteristics and operative characteristics, as shown in - Table 1.

Total intraoperative fluid intake was significantly reduced in R-group, $1,976.7 \mathrm{~mL}(1,661.7 \mathrm{~mL}$ [500-2,000mL] crystalloids and $315 \mathrm{~mL}$ [0-1,350mL] colloids) as compared with S-group 2,598.3 mL (1923 mL [1,000-3,000mL] crystalloids and $675 \mathrm{~mL}[0-1,500 \mathrm{~mL}]$ colloids), $p<0.001$.

Patients in S-group received significantly higher volume of intravenous fluids and blood products during the surgery and in the first three postoperative days as compared with R-group - Table 2; - Fig. 2), except for postoperative day 0 (ICU).

Intraoperatively and in the first three postoperative days overall 11 nonlethal and 1 lethal complications were observed. The rate of complications was significantly higher in S-group as compared with R-group. Specifically, though the number of nonlethal complications was significantly lower in R-Group ( 2 vs. 9 patients, $p=0.042$ ), the difference in lethal complications failed to reach statistical significance (0 vs. 1 patient, $p=\mathrm{ns}$ ) (-Table $\mathbf{3}$ ).
In our study, renal failure did not occur during the followup period. Available data on the first postoperative day have shown that urine output $(2,478.3$ [443.6] in S-group and $1,821.5$ [343.0] in R-group, [ $p=0.172]$ ) and creatinine value (85.60 [22.11] in S-group and 86.43 [19.54] in R-group, [ $p=0.878]$ ) did not significantly differ.

Both the ICU stay (days: 1.2 vs. 1.97, $p<0.001$ ) and postoperative hospital stay (days: 4.33 vs. $6.20, p=0.035$ ) were significantly shorter in R-group as compared with S-group.

\section{Discussion}

This study showed the positive effects in restrictive perioperative fluid management in elective minilaparotomy AAA repair.

Demographic data from our work show that our patient group was comparable to populations in earlier reports. ${ }^{10}$ However, only 12 out of 60 patients in our study were female, which is significantly fewer as compared with the previous studies including up to $50 \%$ of female patients. ${ }^{11,12}$ A lower proportion of female patients in our study might be a consequence of different habits and life standard in different countries.

Significantly lower rate of postoperative morbidity and mortality as anticipated from the POSSUM scores was documented in R- and S-groups comparing to patients undergoing surgical AAA repair through full-size laparotomy on standard

Table 1 Patient and operative characteristics

\begin{tabular}{|c|c|c|c|}
\hline Variable & S group & $\mathrm{R}$ group & $p$ \\
\hline Age (y) (mean [SD]) & $69.34(8.94)$ & $68.64(7.06)$ & $0.737^{\mathrm{a}}$ \\
\hline Gender (M/All patients) & $26 / 30$ & $22 / 30$ & $0.333^{b}$ \\
\hline Body mass index (mean [SD]) & $253.47(49.50)$ & $254.75(46.79)$ & $0.918^{\mathrm{a}}$ \\
\hline Diabetes mellitus & $4 / 30$ & $4 / 30$ & $1^{b}$ \\
\hline Smoker & $24 / 30$ & $22 / 30$ & $0.542^{b}$ \\
\hline Hypertension & $19 / 30$ & $21 / 30$ & $0.584^{\mathrm{b}}$ \\
\hline \multicolumn{4}{|l|}{ Preoperative medications } \\
\hline Aspirin & $25 / 30$ & $27 / 30$ & $0.445^{b}$ \\
\hline$\beta$-Blocker & $12 / 30$ & $11 / 30$ & $0.791^{\mathrm{b}}$ \\
\hline Angiotensin-converting enzyme inhibitor & $15 / 30$ & $14 / 30$ & $0.796^{\mathrm{b}}$ \\
\hline Statin & $18 / 30$ & $19 / 30$ & $0.791^{\mathrm{b}}$ \\
\hline Hemoglobin (mmol/L) (mean [SD]) & $8.33(0.984)$ & $8.65(0.987)$ & $0.987^{\mathrm{a}}$ \\
\hline Physiologic score (mean [SD]) & $17.30(3.26)$ & $16.97(3.53)$ & $0.705^{\mathrm{a}}$ \\
\hline Operative score [mean (SD)] & $15.13(2.37)$ & $14.17(1.70)$ & $0.740^{\mathrm{a}}$ \\
\hline Predicted risk of morbidity (mean [SD]) & $43.36(16.82)$ & $38.15(12.60)$ & $0.179^{\mathrm{a}}$ \\
\hline Predicted risk of mortality (mean [SD]) & $9.87(6.79)$ & $7.64(3.30)$ & $0.112^{\mathrm{a}}$ \\
\hline \multicolumn{4}{|l|}{ Perioperative data } \\
\hline OP time (min) (mean [SD]) & $143.50(34.04)$ & $122.00(32.66)$ & $0.015^{\mathrm{a}}$ \\
\hline CLAMP time (min) (mean [SD]) & $63.17(25.91)$ & $58.23(16.18)$ & $0.380^{\mathrm{a}}$ \\
\hline
\end{tabular}

${ }^{a}$ t-test.

${ }^{\mathrm{b}}$ Difference between two proportions. 
Table 2 Fluid and blood administration

\begin{tabular}{|l|l|l|l|l|l|}
\hline \multirow{2}{*}{} & \multicolumn{2}{|l|}{ S group } & \multicolumn{2}{l}{ R group } & \multirow{2}{*}{ Value (t- test) } \\
\cline { 2 - 5 } & Mean $(\mathrm{mL})$ & SD & Mean $(\mathrm{mL})$ & SD & \\
\hline Crystalloids + colloids (op) & $2,598.33$ & 505.57 & $1,976.67$ & 528.78 & $<0.001$ \\
\hline Crystalloids (op) & $1,923.33$ & 593.46 & $1,661.67$ & 655.44 & 0.115 \\
\hline Colloids (op) & 675.00 & 513.39 & 315.00 & 409.19 & 0.004 \\
\hline Cell saver (op) & 403.66 & 348.46 & 279.07 & 300.76 & 0.144 \\
\hline CE (op) & 176.00 & 336.61 & 67.23 & 170.94 & 0.120 \\
\hline FFP (op) & 101.00 & 319.48 & 119.50 & 413.36 & 0.847 \\
\hline CP (op) & 26.66 & 101.48 & 0.00 & 0.00 & 0.155 \\
\hline Operation total & $3,308.66$ & 802.93 & $2,445.47$ & 914.43 & $<0.001$ \\
\hline Day 0 (ICU) & $2,419.60$ & $1,026.67$ & $2,062.67$ & 708.64 & 0.123 \\
\hline Day 1 & $2,613.00$ & 549.02 & $2,006.77$ & 549.31 & $<0.001$ \\
\hline Day 2 & $2,534.40$ & 816.18 & $1,753.60$ & 580.99 & $<0.001$ \\
\hline Day 3 & $1,907.90$ & 946.64 & 573.23 & 640.16 & $<0.001$ \\
\hline Day 0 (op + ICU) & $5,017.93$ & $1,179.44$ & $4,039.33$ & $1,027.19$ & 0.001 \\
\hline
\end{tabular}

Abbreviations: CE, concentrated erythrocytes; CP, concentrated platelets; FFP, fresh frozen plasma; ICU, intensive care unit; op, intraoperative administration.

fluid regimen. The average physiologic POSSUM score reported in previous studies was 19 and the average surgical POSSUM score ${ }^{13} 16$ and in patients on restricted fluid regimen the average physiologic POSSUM score was 23 and surgical $15 .{ }^{10}$

This difference may be explained by the fact that all surgical procedures were elective, with anesthesiologically well-prepared patients, performed through minilaparotomy approach and that patients in R-group were on reduced fluid regimen during and after the operation.

Regarding the number of postoperative complications, aortic cross-clamp time and overall duration of the procedure, our results are similar to those published in earlier studies ( - Table 4). So far, the studies that have dealt with the reduced and standard fluid administration have reported on a big range of administered fluids during the operation and in postoperative period ( - Table 4 ).

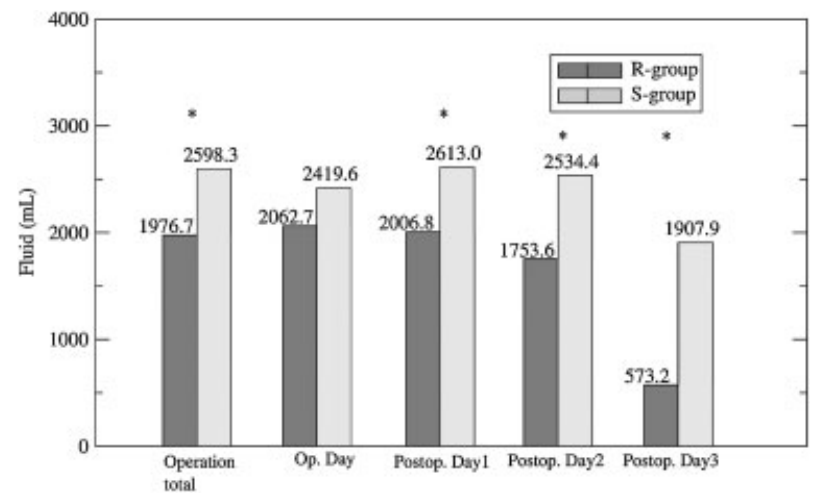

Fig. 2 Fluid administration $\left({ }^{*} p<0.05\right)$.
It may be concluded that the fluids were administered to the patients in postoperative period according to the scheme, with eventual corrections depending on the change of vital parameters. McArdle and coworkers have found that all the patients from the first to the fifth postoperative day in the restrictive fluid administration group have received daily $500 \mathrm{~mL}$ saline solution and $1,500 \mathrm{~mL} 5 \%$ dextrose solution, whereas the patients from standard fluid regimen group have received $1,000 \mathrm{~mL}$ saline solution and $2,000 \mathrm{~mL} 5 \%$ dextrose solution per day. ${ }^{13}$ It is clearly demonstrated that restrictive fluid regimen additionally provides more favorable outcomes, because there is no intestinal edema, so that peristaltic is reestablished faster as well as satisfactory passage, which is needed for patients to start feeding normally.

According to the available data of other authors, duration of ICU stay and postoperative hospital stay at patients with restrictive fluid regimen and those with standard fluid regimen varied widely thus lacking consensus. Whereas some authors reported significant prolongation of hospital stay in the group with restrictive fluid regimen comparing to the group with standard fluid regimen (12.3 vs. 8.3 days), ${ }^{14}$ the others have shown that there were no differences in duration of both ICU and in hospital stay. ${ }^{10}$ Finally, few studies have described significant differences in length of ICU and hospital stay in favor of the groups with restrictive fluid regimen. ${ }^{11,15-18}$ Similar results were confirmed in other studies on patients with restrictive fluid regimen. ${ }^{18}$ In the study of 152 patients who had complex abdominal surgeries in the group with restrictive fluid regimen, period of hospitalization was 8 versus 9 days as compared with the group with standard fluid regimen. ${ }^{18}$ In addition, other studies on reduction in postoperative hospital stay in the group with 
Fluid Regimen in Elective Minilaparotomy Abdominal Aortic Repair Piljic et al.

Table 3 Major complications

\begin{tabular}{|c|c|c|c|}
\hline Complications & $S$ group & $\mathrm{R}$ group & $p$ Value \\
\hline \multicolumn{4}{|l|}{ Cardiovascular } \\
\hline Myocardial infarction & 0 & 0 & - \\
\hline Arrhythmia & 1 & 0 & 0.313 \\
\hline Cardiac failure & 0 & 0 & - \\
\hline \multicolumn{4}{|l|}{ Respiratory } \\
\hline Pneumonia & 0 & 0 & - \\
\hline Pulmonary edema & 1 & 0 & 0.313 \\
\hline Respiratory failure & 0 & 0 & - \\
\hline \multicolumn{4}{|l|}{ Coagulation } \\
\hline Thrombosis & 0 & 0 & - \\
\hline Embolism & 2 & 1 & 0.553 \\
\hline \multicolumn{4}{|l|}{ Hemorrhagic } \\
\hline Bleeding (reoperation) & 0 & 0 & - \\
\hline \multicolumn{4}{|l|}{ Renal } \\
\hline Renal failure & 0 & 0 & - \\
\hline \multicolumn{4}{|l|}{ Infectious } \\
\hline Wound infection & 0 & 0 & - \\
\hline Wound dehiscence & 1 & 0 & 0.313 \\
\hline Other infections & 2 & 0 & 0.150 \\
\hline \multicolumn{4}{|l|}{ Neurological } \\
\hline Depression & 0 & 0 & - \\
\hline Acute delirium & 1 & 1 & 1.000 \\
\hline \multicolumn{4}{|l|}{ Gastrointestinal } \\
\hline Obstipation & 1 & 0 & 0.313 \\
\hline Vomiting & 0 & 0 & - \\
\hline Ileus & 0 & 0 & - \\
\hline Total complications & $9(30)$ & $2(30)$ & 0.042 \\
\hline Lethal outcome & $1(30)$ & $0(30)$ & 0.313 \\
\hline
\end{tabular}

restrictive fluid regimen in comparison with the group with standard fluid regimen have shown even larger differences in the number of days $(5,7$, and 10 days in relation to 7,9 , and 11.5 days). ${ }^{19-21}$

Regarding ICU stay, our results are in line with the majority articles published at the beginning of this century, based on the studies implemented in general abdominal surgery, thoracic surgery, orthopaedics, and vascular surgery. According to the latest researches, duration of total hospitalization was reduced in comparison with the studies from the previous century and it ranges, depending on how well the patient is prepared for surgery before hospitalization, on physical condition of the patient, and surgical technique, as well as manual skills of surgeon and the number of procedures being performed over year. Some authors reported the same duration of hospitalization in the standard and the restrictive fluid regimen group, ${ }^{10,15}$ whereas majority of authors mentioned significantly shorter hospital stay of the patients in the restrictive intra- and postoperative fluid regimen in relation to the group with standard fluid regimen. ${ }^{22-25}$

According to the literature, depending on the size of the cycles with classic elective AAA repairs, mortality ranges from 1.8 to $5 \%{ }^{26}$ to even $9.6 \%{ }^{27-30}$ In our study, we have found nonsignificant differences in 30-day mortality ( 0 vs. 1 , $p=n s)$. We may assume that we were actually underpowered to estimate the differences in such rare outcome. Type and frequency of postoperative complications, in addition to duration of ICU stay and postoperative recovery, are the most important parameters for measuring the success of patient's treatment.

Majority of studies in the field of colorectal and laparoscopic surgery mention significant decrease in the number of complications within the restrictive fluid administration regimen group, although some of them claim that there was no reduction hospital stay. ${ }^{31}$ 
Fluid Regimen in Elective Minilaparotomy Abdominal Aortic Repair Piljic et al.

Table 4 Outcome restrictive versus standard fluid administration

\begin{tabular}{|c|c|c|c|c|c|c|c|c|c|c|}
\hline \multirow[t]{2}{*}{ Author } & \multicolumn{2}{|l|}{$\begin{array}{l}\text { During } \\
\text { operation }\end{array}$} & \multicolumn{2}{|l|}{$\begin{array}{l}\text { Postop } \\
\text { day } 1\end{array}$} & \multicolumn{2}{|l|}{$\begin{array}{l}\text { Postop } \\
\text { day } 2\end{array}$} & \multicolumn{2}{|l|}{$\begin{array}{l}\text { Postop } \\
\text { day } 3\end{array}$} & \multirow[t]{2}{*}{ Complication } & \multirow[t]{2}{*}{$\begin{array}{l}\text { Hospital } \\
\text { stay }\end{array}$} \\
\hline & $\begin{array}{l}\text { R } \\
\text { group }\end{array}$ & $\begin{array}{l}\text { S } \\
\text { group }\end{array}$ & $\begin{array}{l}\text { R } \\
\text { group }\end{array}$ & $\begin{array}{l}\text { S } \\
\text { group }\end{array}$ & $\begin{array}{l}\mathrm{R} \\
\text { group }\end{array}$ & $\begin{array}{l}\text { S } \\
\text { group }\end{array}$ & $\begin{array}{l}R \\
\text { group }\end{array}$ & $\begin{array}{l}\text { S } \\
\text { group }\end{array}$ & & \\
\hline Lobo et al 2002 & 3,100 & 5,700 & & & & & & & $\downarrow$ & $\downarrow$ \\
\hline $\begin{array}{l}\text { Brandstrup } \\
\text { et al } 2003\end{array}$ & 2,700 & 5,400 & 500 & 1,500 & & & & & $\downarrow$ & $\downarrow$ \\
\hline $\begin{array}{l}\text { Nisanevich } \\
\text { et al } 2005\end{array}$ & 1,200 & 2,700 & 2,170 & 2,612 & & & & & $\downarrow$ & $\downarrow$ \\
\hline $\begin{array}{l}\text { MacKay } \\
\text { et al } 2006\end{array}$ & 2,000 & 2,750 & 200 & 2,600 & & & & & $\downarrow$ & $\downarrow$ \\
\hline $\begin{array}{l}\text { Holte } \\
\text { et al } 2007\end{array}$ & 1,640 & 5,050 & & & & & & & $\downarrow$ & $\downarrow$ \\
\hline $\begin{array}{l}\text { Vermeulen } \\
\text { et al } 2009\end{array}$ & 1,500 & 2,500 & & & & & & & $\uparrow$ & $\bar{\uparrow}$ \\
\hline $\begin{array}{l}\text { McArdle } \\
\text { et al } 2009\end{array}$ & 2,626 & 3,308 & 2,000 & 3,000 & 2,000 & 3,000 & 2,000 & 3,000 & $\downarrow$ & $\downarrow$ \\
\hline Lobo $2011^{33}$ & 2,301 & 4,335 & & & & & & & $\downarrow$ & $=$ \\
\hline $\begin{array}{l}\text { Piljić et al, } \\
\text { this article }\end{array}$ & $\begin{array}{l}\text { CR } 1,661 \\
\text { COL } 315\end{array}$ & $\begin{array}{l}\text { CR } 1,923 \\
\text { COL } 675\end{array}$ & $\begin{array}{l}2,006 \\
C L 600\end{array}$ & 2,613 & $\begin{array}{l}1,753 \\
\text { LMF }\end{array}$ & $\begin{array}{l}2,534 \\
C L\end{array}$ & $\begin{array}{l}573 \\
\text { FN }\end{array}$ & $\begin{array}{l}1,907 \\
\mathrm{LMF}\end{array}$ & $\downarrow$ & $\downarrow$ \\
\hline
\end{tabular}

Abbreviations: CL, clear liquids; COL, colloids; CR, crystalloids; FN, full nutrition LMF, liquid and mushy food; postop, postoperative.

Majority of researchers report a decrease in the number of major complications for over $50 \%$ in the restrictive fluid regimen group in comparison with the standard fluid regimen group. ${ }^{6,10-12,17,32}$

More recent clinical studies among the general surgery patients show positive effects in restrictive intra- and postoperative fluid administration, and report a decrease in the number and type of postoperative complications. In the study among the AAA patients operated with classic laparotomy (upper and lower median laparotomy), McArdle and associates found much more complications in the standard fluid regimen group (64\% patients) in relation to the restrictive fluid regimen group (10\% patients). ${ }^{13}$ In the standard fluid regimen group, there were 14 complications in total, including 5 patients with acute delirium, 4 patients with pneumonia, while 1 patient had cardiac arrest, 1 had pulmonary edema, 1 had arrhythmia, and 1 had wound dehiscence and septicaemia. ${ }^{13}$ In the restrictive fluid regimen group, only one patient had acute renal insufficiency. ${ }^{13}$ In 30 days, which was the assessment period for these patients, there was no lethal outcome in any of the groups. ${ }^{13}$

In our study, postoperative complications developed at $18.33 \%$ patients (nine in S-group and two in R-group), which is similar to earlier reports on complication rates. ${ }^{13}$ In our study, renal failure did not occur during the follow-up period. Available data on the first postoperative day have shown that urine output $(2,478.3$ [443.6] in S-group and 1,821.5 [343.0] in R-group, [ $p=0.172])$, and creatinine value (86.43 [19.54] in S-group and 92.27 [28.41] in R-group [ $p=0.58]$ ) did not significantly differ.

Postoperative complications are assigned to hemodynamic instability of patient during the operation and in postopera- tive period. So far, to prevent hemodynamic instability, larger volumes of crystalloid and colloid solutions were applied. However, this research proved that standard (excessive) fluid administration in patients undergoing minilaparotomy AAA repair results in increased rate of postoperative complications. These complications occur due to extravascular accumulation of fluids, caused by systematic inflammatory response, increased microvascular permeability of larger quantities of intravenous solution and prepared blood products, and hemodynamic anesthesia effects.

Regarding the duration of ICU stay, overall postoperative hospital stay, as well as type and frequency of postoperative complications in our study, significantly better results were observed in R-group, which is in line with the majority of studies performed during the past few years in the field of abdominal surgery, thoracic surgery, orthopedics, and vascular surgery.

Occurrence of any complication or several associated complications results in prolongation of hospital stay, which in turn may increase the costs of treatment. Regardless of the fact that clinical and economical relevance of duration of hospital or ICU stay varies widely between different canters in different countries, the rule of thumb is that better clinical outcomes usually result with shorter hospital stay and vice versa. Thus we believe that our results on hospital and ICU stay are valuable and may confirm superiority of one therapeutic strategy over another.

We conclude that restricted intra- and postoperative fluid regimen in elective minilaparotomy AAA repair, for smalldiameter aneurysms that cannot be treated by intravascular techniques, can significantly reduce postoperative complications and length of postoperative hospital stay. 


\section{References}

1 Klokocovnik T, Mirkovic T, Pintar T, Videcnik V. Minilaparotomy for aortoiliac occlusive disease: preliminary results. Tex Heart Inst J 2002;29(4):316-318

2 Klokocovnik T. Minilaparotomy for abdominal aortic aneurysm repair: preliminary results. Tex Heart Inst J 2001;28(3):183-185

3 Strunden MS, Heckel K, Goetz AE, Reuter DA. Perioperative fluid and volume management: physiological basis, tools and strategies. Ann Intensive Care 2011;1(1):2

4 Brandstrup B. Fluid therapy for the surgical patient. Best Pract Res Clin Anaesthesiol 2006;20(2):265-283

5 Rosenberg J. Late postoperative hypoxaemia. Mechanisms and clinical implications. Dan Med Bull 1995;42(1):40-46

6 Nisanevich V, Felsenstein I, Almogy G, Weissman C, Einav S, Matot I. Effect of intraoperative fluid management on outcome after intraabdominal surgery. Anesthesiology 2005;103(1): 25-32

7 Wilmore DW, Smith RJ, O'Dwyer ST, Jacobs DO, Ziegler TR, Wang XD. The gut: a central organ after surgical stress. Surgery 1988; 104(5):917-923

8 Holte K. Pathophysiology and clinical implications of perioperative fluid management in elective surgery. Dan Med Bull 2010;57(7): B4156

9 Joshi GP. Intraoperative fluid restriction improves outcome after major elective gastrointestinal surgery. Anesth Analg 2005; 101(2):601-605

10 Holte K, Foss NB, Andersen J, et al. Liberal or restrictive fluid administration in fast-track colonic surgery: a randomized, double-blind study. Br J Anaesth 2007;99(4):500-508

11 MacKay G, Fearon K, McConnachie A, Serpell MG, Molloy RG, O'Dwyer PJ. Randomized clinical trial of the effect of postoperative intravenous fluid restriction on recovery after elective colorectal surgery. Br J Surg 2006;93(12):1469-1474

12 Shields CJ. Towards a new standard of perioperative fluid management. Ther Clin Risk Manag 2008;4(2):569-571

13 McArdle GT, McAuley DF, McKinley A, Blair P, Hoper M, Harkin DW. Preliminary results of a prospective randomized trial of restrictive versus standard fluid regime in elective open abdominal aortic aneurysm repair. Ann Surg 2009;250(1):28-34

14 Brandstrup B, Tønnesen H, Beier-Holgersen R, et al; Danish Study Group on Perioperative Fluid Therapy. Effects of intravenous fluid restriction on postoperative complications: comparison of two perioperative fluid regimens: a randomized assessor-blinded multicenter trial. Ann Surg 2003;238(5):641-648

15 McArdle GT, Price G, Lewis A, et al. Positive fluid balance is associated with complications after elective open infrarenal abdominal aortic aneurysm repair. Eur J Vasc Endovasc Surg 2007; 34(5):522-527

16 Kabon B, Akça O, Taguchi A, et al. Supplemental intravenous crystalloid administration does not reduce the risk of surgical wound infection. Anesth Analg 2005;101(5):1546-1553

17 Vermeulen H, Hofland J, Legemate DA, Ubbink DT. Intravenous fluid restriction after major abdominal surgery: a randomized blinded clinical trial. Trials 2009;10:50

18 Lopes MR, Oliveira MA, Pereira VO, Lemos IP, Auler JO Jr, Michard F. Goal-directed fluid management based on pulse pressure varia- tion monitoring during high-risk surgery: a pilot randomized controlled trial. Crit Care 2007;11(5):R100

19 Basse L, Raskov HH, Hjort Jakobsen D, et al. Accelerated postoperative recovery programme after colonic resection improves physical performance, pulmonary function and body composition. $\mathrm{Br} \mathrm{J}$ Surg 2002;89(4):446-453

20 Gan TJ, Soppitt A, Maroof M, et al. Goal-directed intraoperative fluid administration reduces length of hospital stay after major surgery. Anesthesiology 2002;97(4):820-826

21 Wakeling HG, McFall MR, Jenkins CS, et al. Intraoperative oesophageal Doppler guided fluid management shortens postoperative hospital stay after major bowel surgery. $\mathrm{Br} \mathrm{J}$ Anaesth 2005; 95(5):634-642

22 Biancari F, Heikkinen M, Lepäntalo M, Salenius JP; Finnvasc Study Group. Glasgow Aneurysm Score in patients undergoing elective open repair of abdominal aortic aneurysm: a Finnvasc study. Eur J Vasc Endovasc Surg 2003;26(6):612-617

23 Noblett SE, Snowden CP, Shenton BK, Horgan AF. Randomized clinical trial assessing the effect of Doppler-optimized fluid management on outcome after elective colorectal resection. Br J Surg 2006;93(9):1069-1076

24 Lobo DN, Bostock KA, Neal KR, Perkins AC, Rowlands BJ, Allison SP. Effect of salt and water balance on recovery of gastrointestinal function after elective colonic resection: a randomised controlled trial. Lancet 2002;359(9320):1812-1818

25 Adesanya AO, Johnston WE. Commentary. Effect of intraoperative fluid management on outcome after intraabdominal surgery. Perspect Vasc Surg Endovasc Ther 2006;18(1):77-79

26 Heyer KS, Modi P, Morasch MD, et al. Secondary infections of thoracic and abdominal aortic endografts. J Vasc Interv Radiol 2009;20(2):173-179

27 Yeung BK, Pearce WH. Surgical management of abdominal aortic aneurysm. Vasc Med 2000;5(3):187-193

28 Pearce WH, Zarins CK, Bacharach JM; American Heart Association Writing Group 6. Atherosclerotic Peripheral Vascular Disease Symposium II: controversies in abdominal aortic aneurysm repair. Circulation 2008;118(25):2860-2863

29 Brady AR, Fowkes FG, Greenhalgh RM, Powell JT, Ruckley CV Thompson SG. Risk factors for postoperative death following elective surgical repair of abdominal aortic aneurysm: results from the UK Small Aneurysm Trial. On behalf of the UK Small Aneurysm Trial participants. Br J Surg 2000;87(6):742-749

30 Hadjianastassiou VG, Tekkis PP, Goldhill DR, Hands LJ. Quantification of mortality risk after abdominal aortic aneurysm repair. $\mathrm{Br} J$ Surg 2005;92(9):1092-1098

31 Abraham-Nordling M, Hjern F, Pollack J, Prytz M, Borg T, Kressner $\mathrm{U}$. Randomized clinical trial of fluid restriction in colorectal surgery. Br J Surg 2012;99(2):186-191

32 Rahbari NN, Zimmermann JB, Schmidt T, Koch M, Weigand MA, Weitz J. Meta-analysis of standard, restrictive and supplemental fluid administration in colorectal surgery. Br J Surg 2009;96(4): 331-341

33 Lobo SM, Ronchi LS, Oliveira NE, et al. Restrictive strategy of intraoperative fluid maintenance during optimization of oxygen delivery decreases major complications after high-risk surgery. Critical Care 2011;15(5):R226 